trên 53 trường hợp ung thư ĐTT giai đoạn I-II, chúng tôi rút ra một số kết luận sau:

MSI-H có tỷ lệ mắc cao hơn u MSS/MSI-L ở giai đoạn I và thẩp hơn ở giai đoạn II. Trong đó, thể LS gặp tỷ lệ cao ở giai đoạn II và thấp nhất ở giai đoạn I.

Ung thư ĐTT giai đoạn I-II có MSI-H chiếm tỷ cao ở các typ nhày, tể bào nhẫn, tủy, hay có xâm nhập lympho vào u và có phản ứng lympho dạng Crohn cao nhất.

\section{TÀI LIÊU THAM KHẢO}

1. Cunningham, JM, Kim CY, Christensen ER, Tester DJ, Parc Y, Burgart LJ, Halling KC, McDonnell SK, Schaid DJ, Walsh Vockley C, Kubly ' V, Nelson H, Michels VV, Thibodeau SN (2001), "The frequency of hereditary defective mismatch repair in a prospective series of unselected colorectal carcinoma", Am J Hum Genet, 69: 780-790. .

2. De, la Chapelle A (2004), "Genetic predisposition to colorectal cancer", Nat Rev Cancer, 769-780.

3. Greenson, JK, Bonner JD, Ben-Yzhak $O$, Cohen HI, Miselevich I, Resnick MB, Trougouboff P, Tomsho LD, Kim E, Low M, Almog R, Rennert G, Gruber SB. Phenotype of microsatellite unstable colorectal carcinomas: Well- differentiated and focally mucinous tumors and the absence of dirty necrosis correlate with microsatellite instability. Am J Surg Pathol 2003; 27: 563- 570.

4. Hall, G, Clarkson A, Shi A, Langford E, Leung H, Eckstein RP, Gill AJ. Immunohistochemistry for PMS2 and MSH6 alone can replace a four antibody panel for mismatch repair defciency screening in colorectal adenocarcinoma. Pathology 2010; 42: 409-413.

5. Kurzawski, G, J. Suchy, T. De . bniak (2004). Importance of microsatellite instability (MSI) in colorectal cancer: MSI as a diagnostic tool. Annals of Oncology 15 (Supplement 4): iv283 - iv284.

6. Amin, MB et al. AJCC Cancer Staging Manual eighth edition. Springer, 2017, 251-395.

7. Boland, CR, Goel A. Microsatellite instability in colorectal cancer. Gastroenterology 2010; 138: 2073-2087.

8. Umar, A, Boland CR, Terdiman JP et al (2004). Revised Bethesda Guidelines for hereditary nonpolyposis colorectal cancer (Lynch syn- drome) and microsatellite instability. J Natl Cancer Inst 2004; 96: 261-268.

9. Jenkins, MA, Hayashi S, O'shea AM et al. Pathology Features in Bethesda Guidelines Predict Colorectal Cancer Microsatellite Instability: A Population-Based Study. Gastroenterology. 2007 July ; 133(1): 48-56.

\title{
GIÁ TRI CỦA CYSTATIN C TRONG CHẨN ĐOÁN SỚM TỔN THƯƠNG THÂ̂N Ở BỆNH NHÂN ĐÁI THÁO ĐƯỜNG TYP 2 TẠI BỆNH VIỆN TRUNG ƯƠNG THÁI NGUYÊN
}

\section{TÓM TẮT}

Bệnh thận do đái tháo đường (ĐTĐ) là biến chứng mạch máu nhỏ xuất hiện sớm, gặp với tỉ lệ cao, là nguyên nhân gây suy thận giai đoạn cuối cân phải lọc máu định kì, việc phát hiện sớm sự suy giảm độ lọc câuu thẩn đối với bênh nhẩn ĐTĐ là hết sức cần thiểt. Mục tiêu: Xác định giá trị của cystatin $\mathrm{C}$ huyết tương trong phát hiện sớm tổn thương thận ở bệnh nhân đái tháo đường týp 2. Đối tượng và phương pháp nghiên cứu: Mô tả cắt ngang trên 89 bệnh nhân ĐTĐ týp 2 điều trị ngoại trú tại Khoa khám bệnh Bệnh viện trung ương Thái Nguyên. Kết quả: Có mối tương quan thuận mức độ chặt chẽ giữa nồng độ cystatin C với creatinin huyết tương, giữa $\mathrm{MLCT}_{\text {cys }}$ với $\mathrm{MLCT}_{\text {cre ở }}$ BN đái tháo đường týp 2; Có mối tương quan nghịch mức độ chặt chẽ giữa nồng độ cystatin C với

*Trường Đại học Y Dược Thái Nguyên **Bênh viển Trung ướng Thái Nguyên Chịu trách nhiệm chính: Bùi Thị Thu Hương Email: huongbuithithu@tnmc.edu.vn Ngày nhận bài: 12.11.2020

Ngày phản biện khoa học: 24.12.2020

Ngày duyệt bài: 4.01.2021
Bùi Thị Thu Hương*, Nguyễn Thu Giang**

$\mathrm{MLCT}_{\text {cre }}$ ở BN đái tháo đường týp 2; Ước lượng MLCT bằng cystatin $C$ làm tăng thêm 25\% (13/89) bệnh nhân suy thận $(M L C T<60 \mathrm{ml} / \mathrm{p})$. Phân tích đường cong ROC với giá trị tới hạn GFR $60 \mathrm{ml} /$ phút. Diện tích dưới đường cong (AUC) của cystatin C là 0,812 lớn hơn AUC của creatinin là 0,711 . Sự khác biệt có ý nghĩa thống kê $(p<0,05)$. Kết luận: Cystatin $\dot{C}$ huyết tương có thể phản ánh được sự giảm mức lọc câu thận sớm ở bệnh nhân Đái tháo đường týp 2.

Tư khóa: CystatinC, bệnh thận do đái tháo đường, mức lọc cầu thận ước tính (eǴFR)

\section{SUMMARY}

VALUES OF CYSTATIN C IN EARLY

DIAGNOSIS OF RENAL DISEASE IN

PATIENTS WITH TYP 2 DIABETES IN

THAINGUYEN NATIONAL HOSPITAL

Diabetic kidney disease (diabetes mellitus) is a small vascular complication that occurs early, with a high rate, is the cause of end-stage renal failure requiring periodic dialysis, early detection of the decrease in filtration Glomerular glomeruli for diabetic patients is extremely necessary. Objective: Determine the value of plasma cystatin $C$ in early 
detection of kidney damage in type 2 diabetes patients. Subjects and research methods: Crosssectional description of 89 type 2 diabetic patients on external treatment residing at the Department of Medical Examination of ThaiNguyen National Hospital. Results: There is a close correlation between the concentration of cystatinC and creatinin plasma, between eGFRcys and eGFRcre in type 2 diabetes; There is a strong inverse correlation between the concentration of cystatin C and MLCTcre in patients with type 2 diabetes; Estimating GFR by cystatin C increased by $25 \%(13 / 89)$ patients with renal impairment $(e G F R<60 \mathrm{ml} / \mathrm{p})$. Analyze the ROC curve with critical value of GFR $60 \mathrm{ml} / \mathrm{min}$. The AUC of cystatin $C$ of 0.812 is greater than that of creatinine AUC of 0.711 . The difference was statistically significant $(p<0.05)$; Conclusions: Plasma cystatin $C$ may reflect an early decrease in glomerular filtration rate in type 2 diabetic patients.

Keywords: CystatinC, diabetic nephropathy, estimated glomerular filtration rate (eGFR)

\section{I. ĐẶT VẤN ĐỀ}

Bệnh thận do đái tháo đường (ĐTÐ) là biến chứng mạch máu nhỏ xuất hiện sớm, gặp với tỉ lệ cao, là nguyên nhân gây suy thận giai đoạn cuối cần phải lọc máu định kì, việc phát hiện sớm sự suy giảm độ lọc cầu thận đối với bệnh nhân ĐTĐ là hết sức cần thiết. Hiện nay các xét nghiệm được dùng sàng lọc bệnh thận do ĐTÐ là theo dõi microalbumin niệu, đánh giá chức năng lọc câu thận bằng định lượng nồng độ creatinin máu và độ thanh thải creatinin. Tuy nhiên, creatinin không phải là xét nghiệm đủ nhạy để phát hiện sớm suy giảm chức năng thận. Vì vậy, việc tìm ra một chỉ điểm sinh học nhạy và đặc hiệu để phát hiện sớm suy giảm chức năng thận ở bệnh nhân ĐTĐ là rất có ý nghĩa. Cystatin C là một protein huyết thanh có trọng lượng phân tử nhỏ và được sản xuất ở hâuu hết các tế bào có nhân trong cơ thể. Cystatin $C$ có thể giúp sàng lọc bệnh thận rộng hơn và sớm hơn trước cả khi trị số creatinin tăng. Đã có nhiêu công trình nghiên cứu xác nhận giá trị của cystatin $C$ như là một chỉ tố sinh học mới trong phát hiện tổn thương thận. Ở Việt Nam, những nghiên cứu về vấn đề này còn chưa nhiều, nên câu hỏi nghiên cứu cần đặt ra là cystatin $C$ có ý nghĩa gì trong phát hiện sớm tổn thương thận ở các bệnh nhân đái tháo đường týp hay không? Vì vậy chúng tôi thực hiện đề tài với mục tiêu: Xác định giá trị của cystatin C huyêt tương trong phát hiện sớm tổn thương thận ở bệnh nhân đái tháo đường týp 2.

II. ĐỐI TƯợNG VÀ PHƯƠNG PHÁP NGHIÊN CứU

2.1. Đối tượng nghiên cứu. 89 bệnh nhân đái tháo đường týp 2, điều trị ngoại trú tại Khoa khám bệnh Bệnh viện trung ương Thái Nguyên

\subsection{Thời gian và địa điểm nghiên cứu}

- Thời gian: Từ tháng 01/2020 đến tháng $10 / 2020$

- Địa điểm: Khoa Khám bệnh, khoa Sinh hóa Bệnh viện Trung ương Thái Nguyên

2.3. Phương pháp nghiên cứu

- Phương pháp nghiên mô tả.

- Thiết kế nghiên cứu hồi cứu.

- Phương pháp chon cỡ mẫu có chủ đích.

2.4 Thiết bị và hoá chất nghiên cứu. Máy xét nghiệm sinh hoá máu AU400 của Olympus, hoá chất của hãng Beckman Coulter.

\subsection{Các chỉ tiêu nghiên cứu}

* Thông tin chung: Tuổi, giới

*Cận lâm sàng: Ure, Creatinin máu, Uric máu, Cystatin máu, Microalbumin niệu, Creatinin niệu.

2.6. Kỹ thuật thu thập số liệu. Tất cả các bệnh nhân nghiển cứu được hỏi bệnh, khám lâm sàng và làm bệnh án theo mẫu thổng nhất.

2.6.1 Tiêu chuẩn chọn bệnh nhân:

*Bệnh nhân được chẩn đoán đái tháo đường theo tiêu chuẩn của ADA - Hoa Kỳ 2015.

*Bệnh nhân được chẩn đoán ĐTĐ týp 2 theo tiêu chuẩn của Tổ chức $Y$ tế Thế giới và vận dụng phù hợp với điều kiện Việt Nam: Người lớn > 40 tuổi; Triệu chứng lâm sàng không rầm rộ; Thường có cơ địa béo phì; Không có biến chứng nhiễm toan ceton; Điều trị lâu dài có hiệu quả bằng chế độ ăn và/hoặc các thuốc viên hạ đường huyết; Bệnh nhân đái tháo đường týp 2 protein niệu âm tính (nhóm bệnh)

*Tiêu chuẩn loai trừ khỏi nghiên cứu

- Đái tháo đường týp 1, đái tháo đường thai nghén hoặc các đái tháo đường khác không phải là đái tháo đường týp 2.

- Bệnh nhân có các biến chứng nặng, cấp tính như: hôn mê nhiễm toan ceton, hôn mê tăng áp lực thẩm thấu, các nhiễm trùng cấp tính...

- Bị ĐTÐ thứ phát sau các bệnh nội khoa hay nội tiết khác (Basedow, hội chứng Cushing...).

- Đang trong đợt mất bù của suy tim, suy gan.

- Suy thận đã lọc máu có chu kỳ

- Sử dụng corticoid trong 1 tháng trước thời điểm nghiển cứu

\subsubsection{Các xét nghiệm cận lâm sàng}

Các xét nghiệm được làm tại Khoa Sinh hoá Bệnh viện Trung ương Thái Nguyên.

- Creatinin huyết thanh định lượng theo phương pháp động học enzym. Kết quả được biểu thị bằng $\mu \mathrm{mol} / \mathrm{l}$. Giá trị bình thường là: nam: $62-115 \mu \mathrm{mol} / \mathrm{l}$, nữ: 53-97 $\mu \mathrm{mol} / \mathrm{l}$.

Ước lượng $M L C T_{\text {cre }}$ theo công thức MDRD (Modification of Diet in Renal Disease): $\operatorname{MLCT}_{\text {cre }}\left(\mathrm{ml} /\right.$ phút $\left./ 1,73 \mathrm{~m}^{2}\right)=186 \times$ (nồng độ 
creatinin/88,4)-1,154x (tuổi)-0,203.

- CystatinC: Định lượng theo phương pháp miễn dịch đo độ đục. Kết quả được biểu thị bằng $\mathrm{mg} / \mathrm{l}$. Giá trị bình thường: 0.4-1.2mg/l.

Ước lượng MLCT cys tính theo công thức được Hội Thận Quốc tế KDIGO khuyến cáo áp dụng (Stevens A đề xuất năm 2008): MLCT $_{\text {cys }}=76,7$ x CysC ${ }^{-1,19}$.

- Microalbumin niệu: Định lượng theo phương pháp miễn dịch đo độ đục. Kết quả được biểu thị bằng $\mathrm{mg} / \mathrm{dl}$. Giá trị bình thường $<2 \mathrm{mg} / \mathrm{dl}$

2.7. Xử lý số liệu: Các số liệu nghiên cứu được xử lý theo phương pháp thống kê y sinh học với phân mêm SPSS 20.0.

2.8. Đạo đức trong nghiên cứu. Nghiên cứu được tiến hành sau khi hội đồng đạo đức của Bệnh viện Trung ương Thái Nguyên thông qua. Đối tượng tham gia nghiên cứu hoàn toàn tự nguyện và có quyền dừng tham gia nghiên cứu hoặc từ chối trả lời bất kỳ câu hỏi nào mà không cân giải thích.

\section{KẾT QUẢ NGHIÊN CứU}

Đặc điểm chung của nhóm nghiên cứu

Tuổi trung bình của các đối tượng nghiên cứu là $71,8 \pm 4,58$, tuổi cao nhất là 85 , thấp nhất là 51 . Tỷ lệ giữa nam là $60 \%$ cao hơn giới nữ là $40 \%$. Giá trị trung bình cystatin $C$ huyết tương là $1,8 \pm$ $1,75(\mathrm{mg} / \mathrm{l})$, giá trị trung vị là $1,5(\mathrm{mg} / \mathrm{l})$, giá trị nhỏ nhất là $0,2(\mathrm{mg} / \mathrm{l})$, lớn nhất là $12(\mathrm{mg} / \mathrm{l})$ và không tuân theo quy luật phân phối chuẩn.

Tỷ lệ tăng cystatin C là 67,4\%.

Bảng 1. Nồng độ Cystatin C của các đôî tượng nghiên cứu theo giới

\begin{tabular}{|c|c|c|c|}
\hline Giới & $\begin{array}{l}\text { Số } \\
\text { BN }\end{array}$ & $\begin{array}{c}\text { Nông độ } \\
\text { Cystatin C } \\
{ }^{X}(\mathrm{mg} / \mathrm{l})\end{array}$ & $\mathbf{p}$ \\
\hline Nam & 56 & $1,73 \pm 1,5$ & \multirow{2}{*}{$p>0,05$} \\
\hline $\mathbf{N} \tilde{u}$ & 36 & $1,96 \pm 2,1$ & \\
\hline
\end{tabular}

Nhận xét: Không có sự khác biệt về nông độ cystatin giữa 2 giới nam và nữ ( $p>0,05)$.

Bảng 2. Môi liên quan tuyến tính giứa Cytatin C với creatinin, độ lọc cầu thận

\begin{tabular}{|c|c|c|c|}
\hline Chỉ số & $\begin{array}{c}\text { Phương } \\
\text { trình tương } \\
\text { quan }\end{array}$ & r & p \\
\hline $\begin{array}{c}\text { Cystatin C } \\
\text { với creatinin }\end{array}$ & $\begin{array}{c}\mathrm{y}=0,012 \mathrm{x}+ \\
0,286\end{array}$ & 0,88 & $<0,05$ \\
\hline $\begin{array}{c}\text { MLCTCys với } \\
\text { MLCTCre }\end{array}$ & $\begin{array}{c}\mathrm{y}=1,1 \mathrm{x}+ \\
65,43\end{array}$ & 0,76 & $<0,05$ \\
\hline $\begin{array}{c}\text { Cystatin C } \\
\text { với MLCT Cre }\end{array}$ & $\begin{array}{c}\mathrm{y}=-15,53 \mathrm{x}+ \\
82,1\end{array}$ & 0,7 & $<0,05$ \\
\hline
\end{tabular}

Nhận xét: - Có mối tương quan thuận mức độ chặt chẽ giữa nồng độ cystatin $C$ với creatinin

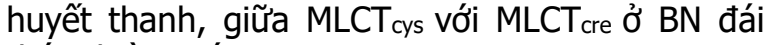
tháo đường týp 2.

- Có mối tương quan nghịch mức độ chặt chẽ

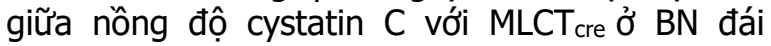
tháo đường týp 2.

Bảng 3. Liên quan giữa MLCT MLCTcreso trong phát hiện sớm bệnh nhân bệnh thận mạn do ĐTĐ ở giai đoạn sớm

\begin{tabular}{|c|c|c|c|c|}
\hline \multicolumn{2}{|c|}{} & \multicolumn{2}{|c|}{ MLCT $_{\text {cre (ml/p) }}$} & Tổng \\
\cline { 2 - 5 } \multicolumn{2}{|c|}{} & $<\mathbf{6 0}$ & $\mathbf{2 6 0}$ & \\
\hline MLCT $_{\text {cysc }}$ & $<\mathbf{6 0}$ & $39(75 \%)$ & $13(25 \%)$ & 52 \\
\cline { 2 - 5 } (ml/p) & $\geq \mathbf{6 0}$ & 0 & $37(100 \%)$ & 37 \\
\hline \multicolumn{2}{|c|}{ Tổng } & 39 & 50 & 89 \\
\hline
\end{tabular}

Nhân xét: Ước lượng MLCT bằng cystatin C làm tăng thêm 25\% (13/89) bệnh nhân suy thận (MLCT<60 ml/p).

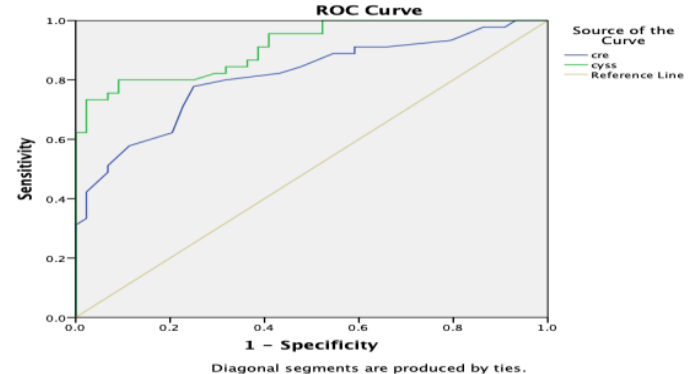

Biêu đồ 1. So sánh giá trị AUC của Cystatin C và Creatinin trong phát hiện sớm bệnh nhân bệnh thận mạn do ĐTÐ ở giai đoạn sớm

Nhận xét: Phân tích đường cong ROC với giá trị tới hạn GFR 60 ml/phút. Diện tích dưới đường cong (AUC) của cystatin C là 0,812 lớn hơn AUC của creatinin là 0,711 . Sự khác biệt có ý nghĩa thống kê $(p<0,05)$.

\section{BÀN LUÂ̂N}

Nghiên cứu trên 89 bệnh nhân đái tháo đường týp 2 điêu trị tại Bệnh viện trung ương Thái Nguyên, chúng tôi thu được một số kết quả sau:

Tuổi trung bình của các đối tượng nghiên cứu

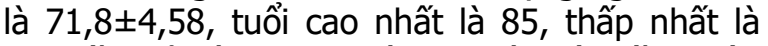
51. Kết quả này cũng phù hợp với một số nghiên cứu khác cho thây: tuổi trung niên và tuổi cao là yếu tố nguy cơ của hội chứng chuyển hóa và kháng insulin[1]. Kết quả nghiên cứu của chúng tôi cũng cho thấy tỷ lệ tăng cystatin $C$ ở bệnh nhân đái tháo đường týp 2 là $67,4 \%$. Kết quả này cũng phù hợp với nhiều nghiên cứu khác [1]. Giá trị trung bình cystatin $C$ huyết tương là $1,8 \pm 1,75(\mathrm{mg} / \mathrm{l})$, giá trị trung vị là $1,5(\mathrm{mg} / \mathrm{l})$, giá trị nhỏ nhất là $0,2(\mathrm{mg} / \mathrm{l})$, lớn nhất là $12(\mathrm{mg} / \mathrm{l})$ và không tuân theo quy luật phân phối chuẩn.

Trong nghiên cứu của chúng tôi, tỷ lệ giới nam cao hơn giới nữ. Tuy nhiên, không có sự 
khác biệt về nồng độ cystatin $C$ giữa 2 giới nam và nữ ( $p>0,05)$ (bảng 1$)$. Bình thường, nam và nữ nếu cùng độ tuổi thì cân nặng và khối lượng cơ trong cơ thể khác nhau, do vậy creatinin có sư khác biêt về giới. Cystatin $C$ được sản sinh ra ở tất cả các tế bào có nhân trong cơ thể với tốc độ hằng định, do vậy không thay đổi theo giới. Nghiên cứu của Trần Quốc Toản (2015) cho thây nồng độ trung bình cystatin $C$ huyết tương của nam ở cả nhóm tổn thương thận và nhóm chứng bệnh khác biệt không có ý nghĩa so với nữ. Ngược lại, giá trị trung bình nồng độ creatinin ở nam cao hơn có ý nghĩa so với nữ ở cả nhóm tổn thương thận và nhóm chứng bệnh. Như vậy, khi ước lượng mức lọc cầu thận bằng cystatin $\mathrm{C}$ thì việc có hay không hiệu chỉnh theo giới cũng ít ảnh hưởng tới kết quả tính toán, ngược lại, ước lượng bằng creatinin thì phải hiệu chỉnh theo giới [1].

Kết quả nghiên cứu cho thấy mối tương quan thuận chặt chẽ giữa cystatin $C$ và creatinin huyết tương ( $r=0,88$; bảng 2). Nghiên cứu của Stickle D. (1998) ở đối tượng bệnh nhi cũng cho kết quả tương tự $(r=0,882 ; n=63)$. Nghiên cứu của Muasscheart $M$ et al. cho thấy tương quan tuyến tính giữa cystatin $C$ và huyết tương creatinin $(r=$ $0,92)$ trong nghiên cứu của mình. Điều này cũng phù hợp với nghiên cứu được thực hiện bởi Borges et al. cho thấy có tương quan chặt giữa cystatin $C$ và creatinin huyết tương $(r=0,80)$. Như vậy, nồng độ cystatin $C$ ở bệnh nhân đái tháo đường tổn thương thận có tương quan chặt chẽ với creatinin huyết tương.

Do creatinin huyết tương đã được xác định là chịu ảnh hưởng của một số yếu tố (giới, tình trạng dinh dưỡng, tình trạng bệnh lý...) do đó, tính mức lọc cầu thận ước lượng dựa vào creatinin huyết tương cần được hiệu chỉnh theo đặc điểm của bênh nhân. Cystatin C có thể thay thế creatinin để ước lượng mức lọc cầu thận ở các bệnh nhân đái tháo đường týp 2 tổn thương thân (công thức được đề nghị của Stevens L.A. (2008)) [4].

Dsa J và cộng sự (2017) đã chỉ ra rằng cả mức độ creatinin và cystatin $C$ huyết tương tăng một cách rõ rệt ở các mức độ suy thận mạn $(p<0,001)$ Ở các đối tượng suy thận mạn có eGFR $\geq 60 \mathrm{~mL} /$ phút $/ 1,73 \mathrm{~m} 2$, khi giá trị trung vị (median) của creatinin huyết tương $(1,01 \mathrm{mg} / \mathrm{dL}$ ) vẫn còn nằm trong giới hạn bình thường thì giá trị trung vị của cystatin huyết tương $(1,34$ $\mathrm{ng} / \mathrm{mL}$ ) đã tăng quá giới hạn tham chiếu trên $(1,09 \mathrm{ng} / \mathrm{mL})$, mặc dù vẫn có sự tương quan dương giữa mức độ creatinin và cystatin $\mathrm{C}$ huyết tương và có sự tương quan nghịch giữa creatinin và cystatin C với eGFR [5]. Như vậy, cystatin C rất có ích trong việc phát hiện những người bị suy thận mạn có eGFR giảm nhe so với creatinin và có thể sử dụng để sàng lọc các bệnh nhân đái tháo đường kém kiểm soát hoặc bệnh nhân tăng huyết áp có mức độ creatinin tăng không rõ ràng.

Ngoài ra, chúng tôi nhận thấy rằng cystatin $\mathrm{C}$ tăng dần theo sự giảm dần độ lọc cầu thận kể cả nhóm tổn thương và không tổn thương thận. Kết quả bảng 3 cho thấy ước lượng MLCT bằng cystatin C làm tăng thêm 25\% (13/89) bệnh nhân suy thận $(M L C T<60 \mathrm{ml} / \mathrm{p})$. Điều đó có thể hiểu là khi có tổn thương thân ở giai đoan sớm đã có sự ảnh hưởng chức năng lọc cystatin $C$ của cầu thận, nồng độ cystatin $C$ tăng lên khi có tổn thương thận ngay cả khi mức lọc cầu thận chưa giảm rõ. Tổn thương thận tăng dần sẽ làm mất dần các nephron nguyên vẹn, khả năng lọc của cầu thận bị ảnh hưởng không những với các chất có trọng lượng phân tữ lớn mà với cả các chất có trọng lượng phân tử nhỏ như ure, creatinin. Hậu quả là nồng độ các chất hòa tan sẽ tiếp tục tăng cao trong máu. Như vậy, cystatin $C$ huyết tương có thể phản ảnh được có hay không có tổn thương thận, mức độ tổn thương thận và sự giảm mức lọc cầu thận.

Sử dụng đường cong ROC so sánh độ nhạy và độ đặc hiệu của cystatin $C$ và creatinin (với giá trị tới han GFR $60 \mathrm{ml} /$ phút). Kết quả cho thấy diện tích dưới đường cong (AUC) của cystatin $\mathrm{C}$ là 0,812 lớn hơn AUC của creatinin là 0,73 . Sự khác biệt có ý nghĩa thống kê $(p<0,05)$. Sự khác biệt cho thấy độ nhạy và độ đặc hiệu của cystatin $\mathrm{C}$ tốt hơn creatinin trong phát hiện tổn thương thận giai đoạn sớm. Nghiên cứu của chúng tôi cũng có kết quả tương tự như trong các nghiên cứu của các tác giả khác [6], [7].

\section{KẾT LUẬN}

Có mối tương quan thuận mức độ chặt chẽ giữa nồng độ cystatin $C$ với creatinin huyết tương, giữa $M^{2} \mathrm{CT}_{\text {cys }}$ với $\mathrm{MLCT}_{\text {cre; }}$ Có mối tương quan nghịch mức độ chặt chẽ giữa nồng độ cystatin $C$ với $M L C T_{\text {cre }}$ ở $B N$ đái tháo đường týp 2; Ước lượng MLCT bằng cystatin C làm tăng thêm 25\% (13/89) bệnh nhân suy thận (MLCT<60 ml/p); Phân tích đường cong ROC với giá trị tới hạn GFR $60 \mathrm{ml} /$ phút. Diện tích dưới đường cong (AUC) của cystatin C là 0,812 lớn hơn AUC của creatinine là 0,711 . Sự khác biệt có ý nghĩa thống kê $(p<0,05)$. Sự khác biệt có ý nghĩa thống kê $(p<0,05)$. Cystatin $C$ huyết tương có thể phản ánh được sự giảm mức lọc cầu thận sớm ở bệnh nhân Đái tháo đường týp 2. 


\section{TÀI LIÊU THAM KHẢO}

1. Trân Quốc Toản (2015), Nghiên cứu nồng đô cystatin c huyết tương, nước tiểu ở bệnh nhân đái tháo đường týp 2 có tổn thương thận, Luận án Tiến sỹ Học viện 103.

2. Yoshiji Ogawaa, Takashi Gotob, Naoki Tamasawaa et al (2015), Serum cystatin C in diabetic patients, Diabetes reseach and clinical practice, Volume 79, Issue 2, Pages 357-361.

3. Alaaeldin M. Bashier, 1 Ayman Aly Seddik Fadlallah, 2,3 Nada Álhashemi,4 Puja Murli Thadani,1 Elamin Abdelgadir,1 and Fauzia Rashid1 (2015), Cystatin C and Its Role in Patients with Type 1 and Type 2 Diabetes Mellitus, Advances in Endocrinology, Volume 2015, 8 pages.

4. David M. Maahs, MD, PHD, 1,2 Nicole Prentice, BS, $1 \mathrm{Kim}$ McFann, PHD, 1 Janet K. Snell-Bergeon, PHD, 1Diana Jalal, MD,2 Franziska K. Bishop,
MS, 1 Brittany Aragon, BS, 1 and R. Paul Wadwa, $M D$ (2011), Age and Sex Influence Cystatin $C$ in Adolescents With and Without Type 1 Diabetes, Diabetes Care. 2011 Nov; 34(11): 2360-2362.

5. Dsa J, Shetty S, Bhandary RR, Rao AV. Association Between Serum Cystatin C and Creatinine in Chronic Kidney Disease Subjects Attending a Tertiary Health Care Centre. J Clin Diagn Res 2017 Apr; 11(4): BC09-BC12.

6. Rigalleau V. et al (2008), "Cystatin $C$ improves the diagnosis and stratification of chronic kidney disease, and the estimation of glomerular filtration rate diabetes", Diabetes and Metabolism. 34, tr. 482 - 489.

7. Yang YS, Peng CH và Lin CK et al (2007), "Use of Serum Cystatin C to Detect Early Decline of Glomerular Filtration Rate in Type 2 Diabetes", The journal of internal medicine. 46, tr. 801 - 806 .

\title{
KHẢO SÁT THỰC TRANG BÊNH NHÂN LIÊTT NỬA NGƯỜI DO ĐộT QUỴ NÃO TẠI BỆNH VIỆ̂̃N Y HỌC CỔ TRUYỀN CAO BẰNG
}

\author{
Vũ Thị Tâm¹, Lê Thị Tuyết Chinh², \\ Vũ Thị Hồng Anh', Vi Thị Thập Lan ${ }^{3}$
}

\section{TÓM TẮT}

Mục tiêu: Khảo sát thực trạng bệnh nhân liệt nửa người do đột quy não tại bệnh viện $Y$ hoc cổ truyền tại Cao Bằng. Đối tượng và phương pháp: Nghiên cứu mô tả trên 180 bênh nhân bi liêt nửa người do đột quy não đã điều trị tại bệnh viện Y học cổ truyền Cao Bằng thời gian từ ngày $1 / 1 / 2019$ đến ngày $1 / 6 / 2020$. Kết quả và kết luận: Tỉ lệ nam giới bị đột quỵ não chiếm đến $73,33 \%$, còn nữ giới chiếm $26,67 \%$. Tỷ lệ bị đột quy não dưới 60 tuổi là $67,22 \%$, trên 60 tuổi là $32,78 \%$. Tỷ lệ dân tộc kinh chiếm 8,89\%, dân tộc tày $47,22 \%$, các dân tộc khác chiếm 43,89\%. Bệnh nhân bị liệt bên trái chiếm $53,89 \%$, liệt bên phải chiếm $46,11 \%$. Đôt quy não do nhồi máu não chiếm tỉ lể lớn đến $71,67 \%$. Sau khi bị tai biến bệnh nhân được đưa đến viên chiếm $63,33 \%$. Tỉ lê bênh nhân bi đột quy não được sử dụng kết hợp thuốc đông y và tây y chiếm tỉ lê cao nhất $69,44 \%$.

Tư khóa: Đột quỵ não, phục hôi chức năng, vật lý trị liệu, nhồi máu não, vận động trị liệu

\section{SUMMARY \\ CURRENT STATUS OF PATIENTS WITH HEMIPARESIS DUE TO STROKE IN CAO BANG HOSPITAL OF TRADITIONAL MEDICINE}

\footnotetext{
${ }^{1}$ Trường đại hoc Y Dược Thái Nguyên

${ }^{2}$ Bệnh viện Y học cổ truyền Cao Bằng

${ }^{3}$ Bềnh viện Trung ương Thái Nguyên

Chịu trách nhiệm chính: Vũ Thị Tâm

Email: bstamphcn@gmail.com

Ngày nhận bài: 20.11.2020

Ngày phản biện khoa học: 25.12.2020

Ngày duyệt bài: 6.01.2021
}

Objective: To evaluate Current status of patients with hemiparesis due to stroke in Cao Bang hospital of traditional medicine. Subjects and methods: Observation study with 180 patients who was hemiparesis due to stroke in Cao Bang hospital of traditional medicine in the period from January, $1^{\text {st }}$ 2019 to June, $1^{\text {st }}$ 2020. Results and conclusions: The proportion of stroke male is $73,33 \%$ while the proportion of stroke female is $26,67 \%$. In terms of age group, the portion of under 60 -year-old group is $67,22 \%$ and the portion of above 60 -year-old group is $32,7 \%$. Regarding to ethnic group, the percentage of Kinh and Tay people is $8,89 \%$ and $47,22 \%$, respectively; while of the other ethnic groups is $43,89 \%$. The left-side hemiparesis group makes up $53,89 \%$ whilst the right-side hemiparesis group accounts for $53,89 \%$. Ischemic stroke makes up a huge proportion, at $71,67 \%$. There is $63,33 \%$ stroke patients are hospitalized. The percentage of patients who are treated with combination of alternative medicine and western medicine is the highest point, at $69,44 \%$.

Keywords: stroke, rehabilitation, ischemic stroke, physical therapy.

\section{I. ĐặT VẤN ĐỀ}

Đột quỵ não đã và đang là vấn đề thời sự cấp thiết của y học nói chung, của ngành phục hồi chức năng nói riêng đối với mọi quốc gia, dân tộc trên thế giới. Tai biến mạch máu não là bệnh lý do nhiêu nguyên nhân khác nhau gây ra, người bệnh có thể tử vong nhanh chóng hoặc nếu sống sốt sẽ để lại nhiều di chứng nặng nề. Theo Nguyễn Văn Đắng di chứng về vận động của đột quy. não là 92,62\%; di chứng nặng là 